\title{
Variação linguística e Prova Brasil: quando o prescrito não dialoga com a reflexão teórica
}

\author{
Linguistic variation and Prova Brasil: when prescription and theory don't match
}

\author{
Carmen Teresinha Baumgärtner ${ }^{1}$ \\ Universidade Estadual do Oeste do Paraná \\ Leandro Wallace Menegolo ${ }^{2}$ \\ Fundação Universidade Federal de Rondônia
}

\begin{abstract}
- RESUMO: Este artigo é o resultado de uma pesquisa que analisa o material de orientação didática da avaliação em larga escala intitulada "Prova Brasil". Mais especificamente, detivemo-nos numa das habilidades cognitivas mensuradas por esse exame nacional, a que trata da variação linguística. O objetivo é o de avaliar se e como as prescrições desse instrumental incorporam as contribuições teóricas da sociolinguística. A metodologia adotada, levando em conta o aspecto da natureza dos dados, foi a do Paradigma Qualitativo, e, considerando o aspecto da maneira de coleta de dados, a tipologia de pesquisa é a documental. Os resultados encontrados na análise dos dados foram o uso intercambiável dos termos "variação", "mudança" e "norma" e a (im)precisão do que deveria ser a pedagogia da variação linguística, que considere as variadas maneiras de uso da língua, adequadas às diferentes situações de interação e combatendo o preconceito linguístico: recomenda-se o tratamento da variação em sala de aula, mas de forma inadequada diante da língua-padrão. Em suma, ao divulgar essa compreensão dos aspectos da língua, os elaboradores do material demonstram manter um entendimento de língua com funcionamento homogêneo, uma visão já superada pelas contribuições sociolinguísticas. Ademais, ao reproduzidos pelos professores em cada sala de aula, favorece a manutenção do status quo, da geração e da circulação de preconceitos acerca da língua.
\end{abstract}

- PALAVRAS-CHAVE: Variação Linguística; Mudança; Norma; Pedagogia linguística.

\section{Introdução}

O trabalho do professor de português do Ensino Básico passa constantemente por reformulações curriculares e, quando o assunto é a heterogeneidade da Língua Portuguesa (e não só dela), tais modificações se refletiram oficialmente há 23 anos com o advento da publicação dos Parâmetros Curriculares Nacionais (de $1 .^{\circ}$ e $2 .^{\circ}$ ciclos, em 1997; de $3 .^{\circ}$ e $4 .^{\circ}$ ciclos, em 1998; do Ensino Médio, em 2002) e de seus desdobramentos (PCN em ação de $1 .^{\circ}$ e $2 .^{\circ}$ ciclos, em 1999; PCN em ação de $3 .^{\circ}$ e $4 .^{\circ}$ ciclos, em1999; PCN+ Ensino Médio, em 2003; Orientações Curriculares para o Ensino

\footnotetext{
${ }^{1}$ Doutora em Estudos da Linguagem pela Universidade Estadual de Londrina - UEL, docente da Universidade Estadual do Oeste do Paraná - UNIOESTE nos Cursos de Graduação em Letras Licenciatura (presencial) e em Letras Libras Licenciatura (Educação mediada por tecnologias), e nos Programas de Pós-Graduação em Letras Mestrado/Doutorado Acadêmico - PPGL, e Programa de Pós-Graduação em Letras - Mestrado Profissional PROFLETRAS na UNIOESTE, Cascavel, Paraná, Brasil, carmen.baumgartner@yahoo.com.br.

${ }^{2}$ Mestre em Estudos da Linguagem pela Universidade Federal de Mato Grosso (2005), Cuiabá, Mato Grosso, Brasil, e, atualmente, professor Assistente II, DE, da Fundação Universidade Federal de Rondônia, Brasil, campus de Vilhena, e doutorando em Letras pela UNIOESTE - Universidade Estadual do Oeste do Paraná, em Cascavel, Paraná, Brasil, leandromenegolo@yahoo.com.br.
} 
Médio, em 2004 e em 2006). As mudanças marcaram a necessidade desse profissional do ensino adotar uma concepção de língua que, em uso por falantes e, até, por escritores, não corresponde à homogeneidade propalada pelo estruturalismo saussureano e pelo gerativismo chomskyano, por exemplo, como se existisse apenas uma (a língua padrão), e as outras fossem uma espécie de não-línguas ou usos "errados" da língua. Esses documentos prescrevem a compreensão de língua em constante mudança e como fenômeno social e almejam essas realizações em salas de aula.

A mudança desse entendimento favorece o respeito às diferenças socioculturais e linguísticas dos estudantes para a eliminação de preconceitos acerca de certos usos da língua e a necessidade de o professor buscar o respectivo preparo teórico para lidar com a questão. Senão, preconceitos vigentes vão ocorrer em na sociedade pena inexistência de "uma pedagogia sensível às diferenças sociolinguísticas dos alunos" (BORTONIRICARDO, 2005, p. 15).

Dizendo de outra maneira, há falta de conhecimento, numa parcela de professores, para se construir um trabalho didático com os conceitos básicos da sociolinguística, sendo um deles o próprio reconhecimento da variação linguística enquanto fenômeno recorrente.

Considerando esse panorama, este texto, resultado de uma investigação orientada pelo paradigma qualitativo e pela tipologia documental, está centrado na relação entre a Variação Linguística e o Ensino, estudando o conteúdo do manual didático da avaliação em larga escala intitulada "Prova Brasil", destinado a professores da 4. ${ }^{a}$ série $/ 5 .^{\circ}$ ano, 8. ${ }^{a}$ série $/ 9 .^{\circ}$ ano do Ensino Fundamental. Detém-se na congruência entre os postulados sociolinguísticos e as prescrições de ensino trazidas por esse manual.

Com esse objeto de análise, tem sua leitura destinada, principalmente, aos professores de Língua Portuguesa que almejam construir um trabalho direcionado à formação de leitores críticos e de cidadãos conscientes de aspectos da Língua que são postos em prática no cotidiano.

O objetivo é avaliar se e como as postulações da sociolinguística figuram no interior do material de instrução da Prova Brasil, considerando o tratamento dado às categorias da "variação", da "mudança", da "norma" e da pedagogia da variação linguística.

Isso posto, este texto é composto, além da introdução, por três partes que são: (1) aspectos da Prova Brasil; (2) a análise do material instrutivo; (3) considerações finais.

\section{0 que é a prova brasil}

Esta seção trata de aspectos dessa avaliação diagnóstica de Língua Portuguesa e de Matemática, de vasto alcance, que é aplicada bienalmente pelo Instituto Nacional de Estudos e Pesquisas Educacionais Anísio Teixeira (INEP), uma autarquia federal vinculada ao Ministério da Educação - MEC -. (BRASIL, 2019).

O desempenho dos estudantes nessa avaliação e o fluxo dos alunos na série avaliada por um programa censitário combinam-se para estipular o Índice da Educação Básica (IDEB) de cada escola para mensuração da aprendizagem da Língua Portuguesa e da Matemática e ser um parâmetro da qualidade da Educação Básica (BRASIL, 2011, p. 4).

O material sobre o exame que analisamos é o de Língua Portuguesa. Ele é assinado pelo INEP, pela Secretaria de Educação Básica e pelo MEC e recebe o nome de "PDE: Plano de Desenvolvimento da Educação: Prova Brasil: ensino fundamental: 
matrizes de referência, tópicos e descritores" (BRASIL, 2011). Esclarece que a avaliação foi criada para "medir" o aprendizado "das competências leitora [...] aplicado em praticamente todas as crianças e jovens matriculados na quarta e na oitava séries [quinto e nono anos] [...]." (BRASIL, 2011, p. 6) para "garantir o direito ao aprendizado dessas competências cognitivas básicas e gerais” (BRASIL, 2011, p. 6).

O documento almeja contribuir com a difusão dos pressupostos teóricos que embasam essa avaliação, o que ajudaria o professor, demais profissionais da área da educação e a sociedade a dimensionar os problemas educacionais e direcionar "a formulação, a implementação e a avaliação de políticas públicas educacionais que conduzam à formação de uma escola de qualidade" (BRASIL, 2011, p. 6)

Ao professor, o material anseia que esse profissional reflita sobre sua prática na sala de aula, considere os conhecimentos ali disponibilizados e desenvolva as habilidades que seriam necessárias para se alcançar "as competências exigidas na educação básica" (BRASIL, 2001, p. 6), ou seja, as habilidades ali fixadas.

O aprendizado dessas habilidades, consideradas "básicas e essenciais" no instrumental, seria "mensurado" pelo número de acertos marcados na prova e determinaria os níveis de competência leitora de cada estudante (BRASIL, 2011, p. $7 ; 10)$.

Em 1997, foram desenvolvidas as "Matrizes de Referência", uma lista de habilidades que os alunos deveriam dominar em cada série avaliada, e teria se chegado a ela por meio de uma consulta nacional. Em 2001, essas matrizes foram atualizadas em razão da disseminação dos PCN e estão vigendo (BRASIL, 2008, p. 11-13) ${ }^{3}$. Elas englobam o que estaria contemplado nos currículos nacionais e, o que se cobra na prova é o que seria possível "aferir" pelo tipo de instrumento de medida utilizado (BRASIL, 2011, p. 17).

A matriz de referência de Língua Portuguesa apresenta tópicos ou temas com descritores. Esses descritores indicariam as habilidades a serem avaliadas e, pressupostamente, trabalhadas pelo professor de português junto a seus alunos. Cada descritor seria a associação entre os conteúdos curriculares e as operações mentais que teriam sido ou deveriam ter sido desenvolvidas pelo aluno, pois traduzem as respectivas habilidades (BRASIL, 2011, p. 18).

Nesse sentido, para ser considerado competente em Língua Portuguesa, o aluno precisaria demonstrar o domínio dessas habilidades, pois o capacitariam a viver em sociedade para atuar, de maneira adequada e relevante, nas mais diversas situações sociais de comunicação (BRASIL, 2011, p. 19).

Adiante, apresentamos partes da matriz de referência, na qual mantivemos apenas os chamados "tópicos". Eles são constituídos, respectivamente, de "descritores" ou "habilidades" e totalizam o número de 21. Mantivemos intocável apenas o último tópico, de número IV, intitulado de "Variação Linguística", por ser o único a estar relacionado ao objeto de análise.

\footnotetext{
${ }^{3}$ Ver o Quadro 1: Matrizes de Referência para elaboração da Prova Brasil, adiante exposto.
} 


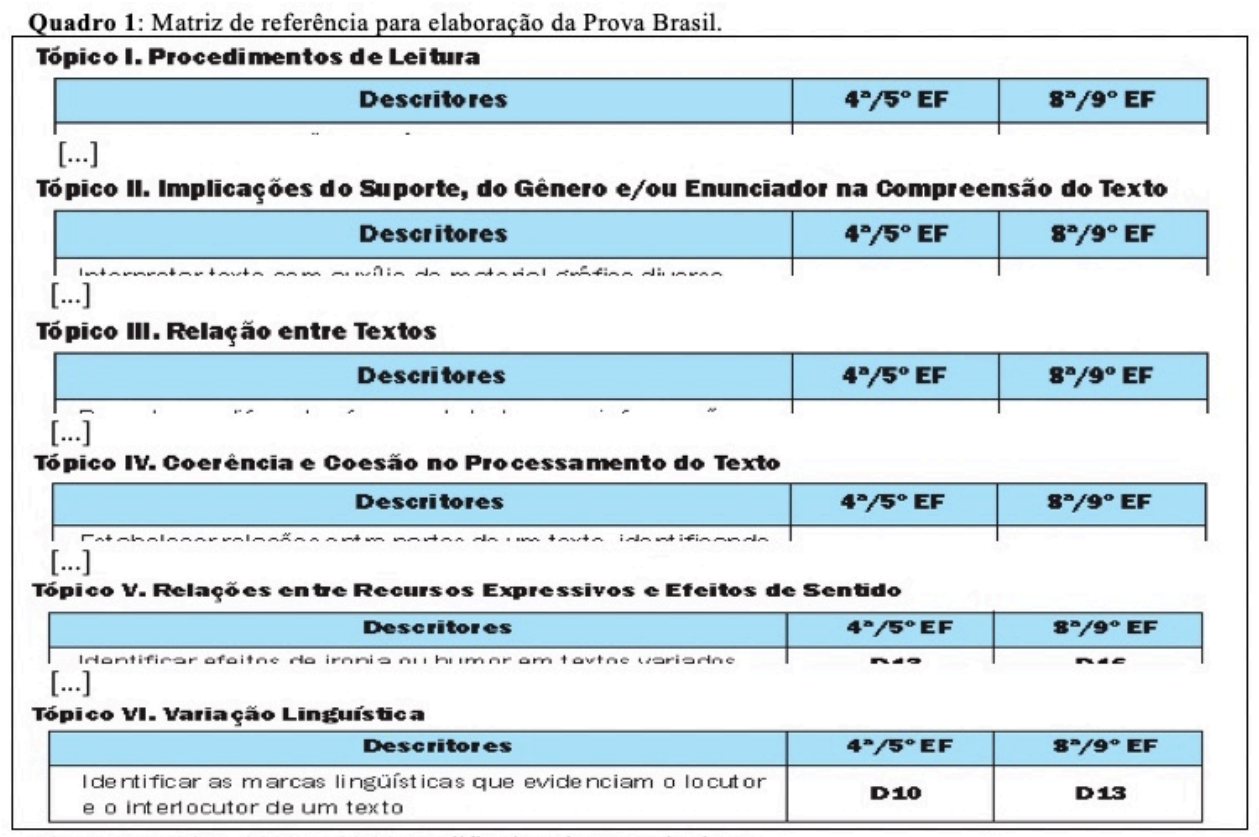

FONTE: BRASIL, 2011, p. 22.23, modificado pelos pesquisadores.

Como exposto no quadro, a questão interpretativa da prova que avalia a habilidade correspondente ao tópico ligado à variação linguística versa sobre se o estudante consegue "identificar as marcas linguísticas que evidenciam o locutor e o interlocutor de um texto" (BRASIL, 2011, p. 23).

Na próxima seção, analisamos o que o material sobre a Prova Brasil (BRASIL, 2011) entende ser o tópico de número 6 e a sua respectiva habilidade a ser "aferida".

\section{As prescrições do instrumental e as contribuições da sociolinguística}

Após realizarmos a leitura de todo o documento, selecionamos, identificamos e analisamos os trechos específicos que se relacionam com a temática da variação linguística. O conteúdo desses trechos se encontra no intervalo das páginas 54 até a $56 \mathrm{e}$ da página 101 até a 103 (BRASIL, 2011). Lembramos que são demonstrativos de como os elaboradores desse documento entendem a temática e, pressupostamente, esperam que essa compreensão seja compartilhada pelos professores de Língua Portuguesa aos seus alunos da $4 .^{\mathrm{a}}$ série $/ 5 .^{\circ}$ ano e da $8 .^{\mathrm{a}}$ série $/ 9 .^{\circ}$ ano.

TRECHO 1: A língua varia e é multiforme.

Que a língua não é um sistema invariável e uniforme já sabemos, embora, nem sempre, aceitemos facilmente esse caráter de mutabilidade das línguas como um processo natural e inerentemente válido.

FONTE: BRASIL, 2006, p. 54, grifos nossos.

Nesse trecho, vê-se que os elaboradores do material amparam-se no entendimento de língua enquanto um sistema variável e multiforme. Estudiosos da sociolinguística concordam com essa afirmação como, por exemplo, Labov, que demonstrou, nos idos de 1960, o caráter variável e heterogêneo da língua: 
Os dados empíricos confirmam plenamente a existência de variação e de estruturas heterogêneas nas comunidades linguísticas investigadas. É a existência de qualquer outro tipo de comunidade que pode ser posta em dúvida. (...) chegamos à conclusão nos últimos anos de que essa a situação normal é a de que a heterogeneidade não é apenas comum, mas é também o resultado natural de fatores linguísticos básicos. Postulamos que disfuncional seria a ausência de mudança de estilo e de sistemas multi-estratificados de comunicação (LABOV, 2008, p. 148, grifos nossos).

Por isso, esse linguista defende a necessidade de se analisar os fatores linguísticos e extralinguísticos envolvidos numa determinada escolha linguística. Para ele, fatores dessa natureza concorrem simultaneamente na decisão do usuário da língua proferir/preferir uma forma em detrimento de outra(s) e os chama de "motivações em competição". Cabe ao pesquisador-linguista determiná-las, pois, seja qual for a escolha do falante, exprime a aplicação de uma determinada regra (ou norma) que precisa ser trazida à tona (CAMACHO, 2010, p. 149).

Seguindo o pensamento de Camacho, Cezário e Votre esclarecem haver três tipos básicos de variação linguística:

(a) variação regional, associada a distâncias espaciais entre cidades, estados, regiões ou países diferentes; (b) variação social: associada a diferenças entre grupos socioeconômicos, compreende variáveis já citadas, como faixa etária, grau de escolaridade, procedência, etc.; (c) variação de registro: tem como variantes o grau de formalidade do contexto interacional ou do meio usado para a comunicação, como a própria fala, o e-mail, o jornal, a carta, etc. (CAMACHO, CEZÁRIO; VOTRE, 2008, p. 144, grifos dos autores).

Entretanto, o conteúdo do Trecho 1 relaciona a propriedade de a língua não ser um sistema "invariável" ao "caráter de mutabilidade das línguas...", ou seja, a pressuposta característica da variação linguística significar o mesmo que sua mudança. Entretanto, Tarallo (1985, p. 63) difere: "nem tudo o que varia sofre mudança; toda mudança linguística, no entanto, pressupõe variação. Variação, portanto, não implica mudança; mudança, sim, implica sempre variação. Mudança é variação!”. Em outras palavras, na Língua Portuguesa, encontramos pronúncias diferentes para a mesma palavra, como leite, que pode ser realizada como "leitchi" ou como diria um morador de Curitiba-PR, "leitE”, configurando uma variação e não uma mudança linguística.

A mudança linguística só ocorre, para Chagas (2002, p. 150), quando surge uma inovação que persiste no uso a ponto de ser incorporada e difundida, gradualmente, pelos falantes de uma comunidade. Interferem, segundo Cezario e Votre (2008, p. 150151) “[...] fatores sociais, refletindo as lutas pelo poder, o prestígio entre classes, sexos e gerações. Mas, para ocorrer a mudança, é necessário um período de variação entre formas".

Enquanto o trecho 1 não dá conta da diferença entre "variação" e "mudança", o próximo trecho versa sobre as características individuais e coletivas dos indivíduos na prática da linguagem em situações de interação verbal. 
TRECHO 2: As especificidades individuais e coletivas dos falantes.

Qualquer atividade de interação verbal envolve situações e sujeitos diversificados, marcados por especificidades individuais e coletivas, que, naturalmente, vão manifestar-se no modo de falar, no padrão de escolha das palavras e das estruturas gramaticais.

FONTE: BRASIL, 2006, p. 54, grifos nossos.

É consenso entre os linguistas que entendem a linguagem como prática social que os sujeitos envolvidos numa interação verbal são afetados por fatores individuais e coletivos. Mas, esses pesquisadores esclarecerem que "os modos de falar" estão coercitivamente atrelados à variação dialetal e não dependem tanto (para não dizer que não dependem) da ação do falante, uma vez que ele está sujeito a essa variação. Já a "escolha das palavras e das estruturas gramaticais" configuram a variação estilística e, essa sim, é "maleável" pelo usuário, uma vez que depende de fatores contextuais, como a imagem feita por ele do seu ouvinte, daí advindo os ajustes (CEZARIO; VOTRE, 2008, p. 145). Consoante Cezario e Votre (2008, p. 146), "Cada pessoa tem um enorme repertório linguístico que a torna capaz de adaptar sua linguagem a diferentes situações vividas".

O trecho 2 contemplou quase que integralmente contribuições linguísticas. O trecho seguinte, número 3 , trata da adequação da variação escolhida a uma determinada situação de uso.

TRECHO 3: As variações X adequações a cada situação.

Perceber tais variações como um processo natural das línguas é desenvolver a capacidade de perceber como legítima a atitude do sujeito de recorrer a variações de usos para adequar-se às condições particulares de cada situação.

FONTE: BRASIL, 2006, p. 54, grifos nossos.

Nele, termo "tais variações" é empregado para fazer referência ao "caráter [natural e válido] de mutabilidade das línguas". Todavia, já vimos que "Mudança" e "Variação" não significam a mesma coisa e, além disso, nem sempre quando há variação, há, obrigatoriamente, uma mudança.

Quanto à outra metade do trecho 3 , como já vimos que a língua varia em níveis dialetais e em níveis de registro, é problemático atribuir, vagamente, a recorrência às "variações de usos". Quais variações? Dialetais ou de registro? Todo usuário recorre às variações em níveis de registro para "adequar-se às condições particulares de cada situação"?

TRECHO 4: Respeito às diversidades culturais.

Numa perspectiva bem mais ampla, recorrer a variações representa $o$ reconhecimento da língua como manifestação das diversidades culturais; representa, ainda, o respeito pelo estatuto de igualdade de todos os cidadãos frente ao exercício da faculdade da linguagem.

FONTE: BRASIL, 2006, p. 54, grifos nossos.

Nota-se um ponto positivo nas instruções do material. Trata-se de entender e reconhecer a prática diversificada da linguagem como uma manifestação cultural. Tal reconhecimento denota respeito pela igualdade de todos quando se pratica a língua. 
TRECHO 5: identidade do usuário e do ouvinte e domínio das variações.

Descritor 10 - Identificar as marcas lingüísticas que evidenciam o locutor e o interlocutor de um texto

Que habilidade pretendemos avaliar?

Por meio de itens deste descritor, pode-se avaliar a habilidade de o aluno identificar quem fala no texto e a quem ele se destina, essencialmente, pela presença de marcas lingüísticas (o tipo de vocabulário, o assunto etc.), evidenciando, também, a importância do domínio das variações lingüísticas que estão presentes na nossa sociedade.

FONTE: BRASIL, 2006, p. 54, grifos nossos.

O trecho cria a expectativa de, por meio do que se fala, ser possível identificar "quem", "para quem" e qual a importância de se dominar as variações linguísticas.

Para Beline (2002, p. 128), a variação linguística "pode chegar até o nível do indivíduo", mesmo vivendo numa comunidade. Contudo, deverá "haver semelhanças entre a língua que ele fala e a que os outros membros da comunidade falam". Nesse contato com outros da sua comunidade é que serão conhecidas as fronteiras para a sua variação individual.

E complementa:

[...] a conclusão a que se chega é a de que as diferenças entre os indivíduos de uma mesma comunidade de fala não poderão ser de natureza gramatical, ou seja, os pesos relativos dos efeitos dos contextos linguísticos no uso de variante pelos diferentes falantes de uma comunidade deverão ser os mesmos ou ser muito próximos. As diferenças que percebemos entre indivíduos de uma mesma comunidade, portanto, são diferenças no nível geral de usar um fenômeno variável (BELINE, 2002, p. 135).

TRECHO 6: variações da fala em texto escrito.

Essa habilidade é avaliada em textos nos quais o aluno é solicitado a identificar o locutor e o interlocutor nos diversos domínios sociais, como também são exploradas as possíveis variações da fala: linguagem rural, urbana, formal, informal, incluindo as linguagens relacionadas a determinados domínios sociais, como cerimônias religiosas, escola, clube etc.

FONTE: BRASIL, 2006, p. 54, grifos nossos.

Embora não esteja escrito na primeira parte do fragmento, avalia-se essa habilidade em textos "escritos". Admite-se que a prática de "variação da fala" é "naturalmente" perceptível num texto escrito. Contrariando, Chagas (2002) sustenta: 
Se nos limitarmos à forma como a escrita registra a pronúncia dos sons e palavras do português, por exemplo, podemos constatar facilmente que já há algum tempo vários tipos de palavras tiveram sua pronúncia alterada, mas continuam a ser grafadas da mesma forma. Por exemplo, palavras como ouro, beijo ou cadeira não são mais pronunciadas ela maioria dos falantes com ditongo na sílaba tônica, mas continuam a ser grafadas dessa forma. Esse afastamento da língua escrita e da língua falada é algo normal e que pode ser verificado em qualquer língua que seja representada graficamente (p. 141).

$[\ldots]$

[...] as letras da escrita atual não correspondem uma a uma a sons diferentes (p. 143)

$[\ldots]$

[...] a língua escrita não reflete todas as mudanças que ocorrem na língua falada (p. 147).

Chama-se "as possíveis variações da fala" de "linguagem rural, urbana, formal, informal", uma visão bastante limitada e dicotômica das possibilidades de variação de uma língua na modalidade falada. Passa a impressão de que a língua falada, quando varia, sempre é nos extremos de suas possibilidades: ou rural ou urbana, ou formal ou informal. Passa a impressão, também, de que a língua escrita não varia!

Incluem-se "as linguagens relacionadas a determinados domínios sociais, como cerimônias religiosas, escola, clube etc." nas "possíveis variações da fala", como se não houvesse escrita nesses "domínios sociais". Além disso, desde quando linguagens relacionadas a esses domínios e a outros são "variações da fala"? Chamá-las dessa maneira demonstra uma visão bastante limitada da diversidade variacional e, seguindo esse raciocínio, atrela, a cada domínio, uma variação de fala, o que, consequentemente, tornaria quase incalculável o aspecto quantitativo da pesquisa sociolinguística. Ademais, demonstra desconhecimento do conceito de "comunidade de fala", locus onde o pesquisador das línguas estuda e estabelece os parâmetros da variação linguística.

Sobre como a linguagem funciona em subcomunidades, Cezario e Votre (2008) argumentam:

\begin{abstract}
Nas comunidades organizam-se agrupamentos de indivíduos constituídos por traços comuns, a exemplo de religião, lazeres, trabalho, faixa etária, escolaridade, profissão e sexo. Dependendo do número de traços que as pessoas compartilham, e da intensidade de convivência, podem constituir-se subcomunidades linguísticas, a exemplo dos jornalistas, professores, profissionais da informática, pregadores e estudantes (CEZARIO; VOTRE, 2008, p. 148).
\end{abstract}

TRECHO 7: ambiente adequado para um determinado uso: tá.

Com este item, podemos avaliar a habilidade do aluno em identificar as marcas lingüísticas que evidenciam o domínio social, ou seja, o ambiente em que a palavra "tá" é mais comumente empregada em vez de "está": se na escola ou em conversa com os amigos. O aluno também é solicitado a identificar se essa mesma marca lingüística "tá" é normalmente estudada nas gramáticas ou encontrada nos livros técnicos.

FONTE: BRASIL, 2006, p. 54.

Analisando, causa estranheza afirmar que o emprego da palavra "tá" determinará o "domínio social" (ambiente) do qual ela é mais comum. Além disso, em "a palavra 'tá' é mais comumente empregada em vez de 'está': se na escola ou em conversa com

Traços de Linguagem, Cáceres, v. 4, n. 2, p. 102-116, 2020. 
os amigos", perguntamos: "conversa com os amigos" é um "ambiente", um espaço tanto quanto o é a "escola"?

As alternativas dadas como possíveis respostas fariam o leitor raciocinar se o uso cobrado no item avaliativo é do domínio das gramáticas ou dos livros técnicos.

$\mathrm{Na}$ via oposta, "Uma das contribuições da pesquisa sociolinguística foi a constatação de que muitas formas não-padrão também ocorrem na fala de pessoas com nível superior, principalmente nos momentos mais informais" (CEZÁRIO; VOTRE, 2008, p. 142).

Segundo Pretti (2003) "O uso de formas tais como "cê" e "tá" não seria adequado numa conferência ou numa circunstância em que se dirige a um superior, são, todavia, perfeitamente plausíveis numa conversa familiar, entre amigos, ou outra situação qualquer. Por outro lado, seria inadequado, da mesma forma, o uso à mesa, de pai para filho, de uma expressão do tipo 'prezado filho, faça-me o obséquio de passar o bule de chá'" (p. 40).

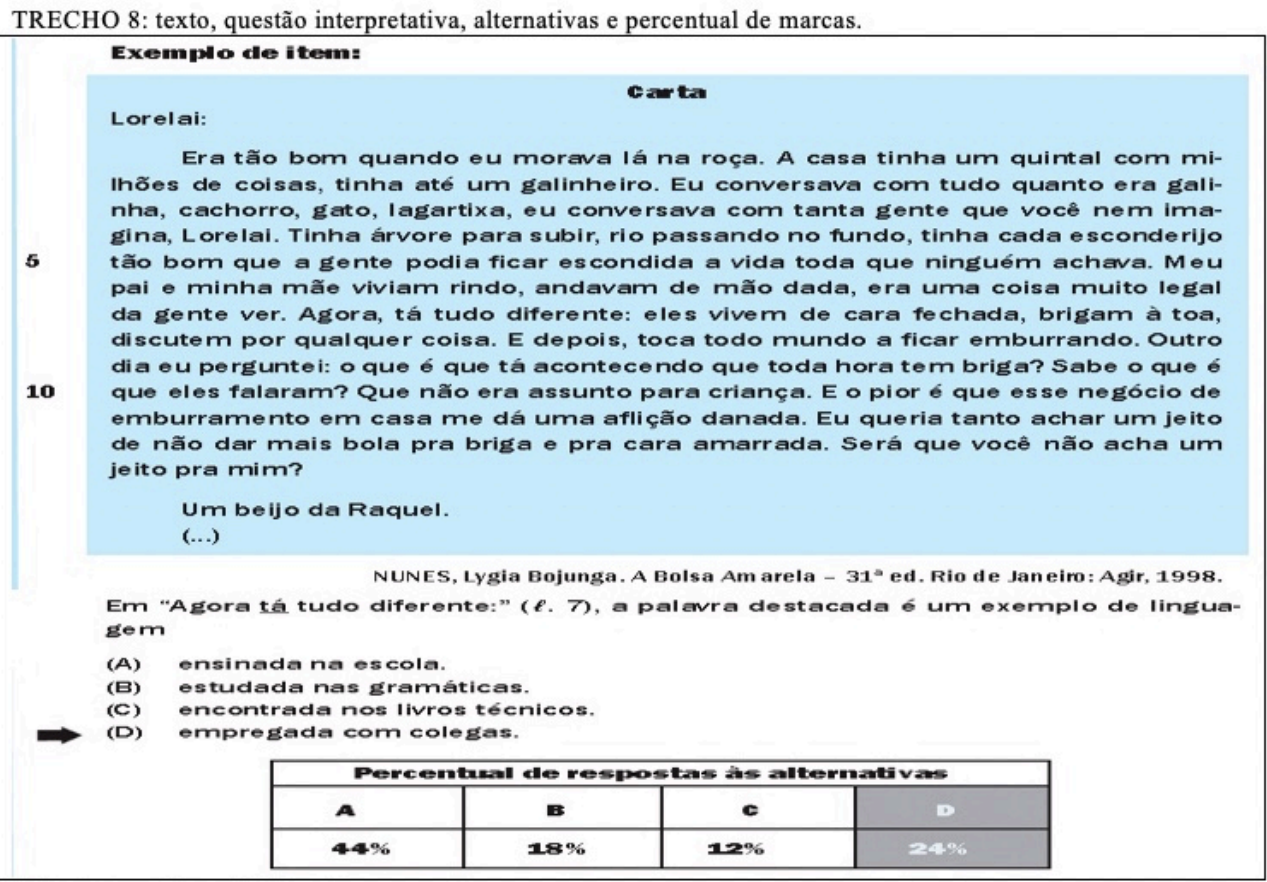

FONTE: BRASIL, 2006, p. 55.

TRECHO 9: análise das marcações: variação X registro.

O que o resultado do Item indica?

Embora o texto que dá suporte a este item seja simples, com vocabulário acessível à $4^{\mathrm{a}}$ série $/ 5^{\circ}$ ano, percebe-se, pelo resultado apresentado, que os alunos não desenvolveram a habilidade requerida pelo descritor 10 . Um percentual baixíssimo acertou o item (24\%), o que denota pouca familiaridade com a questão da variação lingüística e dos registros usados pelos falantes.

FONTE: BRASIL, 2006, p. 55.

Pela primeira vez, a variação linguística é diferenciada "dos registros", embora de forma equivocada. Variação de um lado, registros de outro, como se não fossem essas as formas de variação de uma língua e, além disso, fossem conhecimentos necessários para um aluno de $4 .^{\mathrm{a}}$ série $/$. $^{\circ}$ ano. Novamente, não se tem uma clareza de 
que a língua varia em níveis de dialeto e em níveis de registro. Entende-se que "variação linguística" é uma coisa e "registros usados", outra.

Desconsidera-se também que a ocorrência de "tá", no texto, foi numa situação de intimidade, algo perfeitamente legítimo e comum. Raquel escreve uma carta para a amiga Lorelai, ambas personagens de "A bolsa amarela", de Lygia Bojunga Nunes.

TRECHO 10: desconhecimento da variação e das normas de adequação da fala.

Observe-se, ainda, que uma expressiva maioria de alunos optou pela alternativa incorreta "A", com percentual de respostas muito superior à alternativa correta "D", possivelmente, porque seguiu a pista verbal "escola" para relacionar o ambiente onde a palavra "tá" é usada ou até por desconhecer a questão da variação lingüística.

Os demais alunos foram para as alternativas incorretas " $\mathrm{B}$ " $\mathrm{e}$ "C", demonstrando que, possivelmente, desconhecem as normas sociais e culturais que definem a adequação da fala.

FONTE: BRASIL, 2006, p. 55.

O fato de a maioria marcar a alternativa "(A) ensinada na escola" não significa, necessariamente, que os leitores não saibam o que é "variação linguística". E sim, pode ter ocorrido uma motivação para a não marcação de qualquer uma das outras alternativas em virtude de não serem do contato diário do estudante. Vejamos: "(B) estudada nas gramáticas" pode não ter sido a preferida porque não é um objeto de estudo e manuseio comum para estudantes desse ciclo da aprendizagem. A mesma justificativa é cabível para a não ocorrência, na maioria das marcações, da alternativa "(C) encontrada nos livros técnicos". O fato de a maioria marcar a alternativa "(A) ensinada na escola" pode ser pelo fato de ser uma forma altamente praticável no ambiente escolar, inclusive pelos usuários de posição social mais prestigiada, como os educadores.

Sobre normas para adequação da fala, Modesto (2004, p. 48), recorda Labov, quando estudou as diferenças nos usos da linguagem em seu contexto social, chamando de "variação estilística". Labov percebeu a não utilização da língua da mesma forma em todas os momentos, implicando a escolha de variadas possibilidades de expressão, constituindo um continuum por ir da máxima informalidade até a máxima formalidade.

TRECHO 11: recomendações: razão para o estudo da variação.

Que sugestões podem ser dadas para melhor desenvolver essa habilidade?

Naturalmente, essa competência (variação lingüística) deve ser trabalhada na sala de aula para que os alunos possam desenvolver as habilidades de reconhecer e identificar as marcas lingüísticas empregadas nos diversos domínios sociais.

FONTE: BRASIL, 2006, p. 55.

O instrumental de orientação docente declara a motivação para o estudo da variação linguística: conhecer as "marcas linguísticas" pertencentes a esse ou aquele "domínio social", uma compreensão bastante limitada do porquê de trabalhar com essa temática na sala de aula. Parece confirmar Bagno (2013):

A utilização dos conceitos advindos da sociolinguística, toda a discussão 'politicamente correta' em torno do fenômeno da variação e o aparente combate ao preconceito linguístico só servem para, ao fim e ao cabo, fazer valer o que sempre valeu: uma utopia linguística, um fantasma de língua [...] (p. 117-118). 
TRECHO 12: metodologia: textos escritos.

Para isso, o professor deve selecionar textos que evidenciem eventos de letramento com larga utilização das variantes lingüísticas. Temos, como exemplo, letras de música onde aparecem variantes de pronomes de tratamento, tirinhas, especialmente as de Chico Bento, revistas em quadrinho, trechos de diário, narrativas etc.

FONTE: BRASIL, 2006, p. 55.

Dentro da perspectiva da recomendação anterior, a de estudar a variação para se "identificar as marcas lingüísticas empregadas nos diversos domínios sociais", o prescrito didático agora lança mão de como desenvolver esse ensino: pela seleção de textos "escritos", não explicitados, mas esperados pelas sugestões dadas em seguida à recomendação. Já vimos que os textos escritos não são os mais adequados para o trabalho com a variação linguística.

Quanto aos exemplos de materiais textuais, "letras de música onde aparecem variantes de pronomes de tratamento, tirinhas, especialmente as de Chico Bento, revistas em quadrinho, trechos de diário, narrativas etc.", tem-se, em Bagno (2013), uma crítica severa e alerta para a impropriedade:

O problema é querer transformar essas revistinhas em material pedagógico para a abordagem da variação linguística. O desenhista não tem nenhuma obrigação de representar fielmente a fala de seus personagens, até porque uma representação cem por cento fiel só poderia ser feita por meio de transcrições fonéticas detalhadas o que simplesmente tornaria as revistas ilegíveis (BAGNO, 2013, p. 85).

TRECHO 13: língua padrão X língua não-padrão.

No entanto, é de fundamental importância que o professor, ao lidar com alunos que utilizam exemplos da língua não-padrão, identifique as diferenças e conscientize os alunos quanto a essas diferenças.

FONTE: BRASIL, 2006, p. 56.

No trecho anterior, aparece, pela primeira vez, a terminologia "língua nãopadrão" para se referir aos usos atribuídos unicamente à língua falada. Confunde-se e se implícita a necessidade de o ensino de um padrão e que as modalidades da fala não se encaixam nesse padrão. O material não explica o que seria o "padrão", mas, ao qualificar de "não-padrão" os usos da língua falada, pressupõe ser padrão apenas o constante em textos escritos.

Contrariamente, Leite (2005) argumenta:

Não faltam, porém, aqueles que se insurgem contra o fato de a língua variar. Para esses, ela é entendida como uma entidade monolítica, cuja única face é aquela descrita nos manuais de gramática tradicional e nos dicionários. [...] Isso, porém, não é verdade, e, o que é pior, essa norma da gramática não é efetiva e cabalmente realizada por nenhum falante (LEITE, 2005, p. 184). 
TRECHO 14: pedagogia sensível.

4.9. Considerações finais - Língua Portuguesa

Os itens apresentados foram aplicados no Saeb e na Prova Brasil de $4^{\mathrm{a}}$ e $8^{\mathrm{a}}$ séries, $5^{\circ}$ e $9^{\circ}$ anos do ensino fundamental. Eles revelam a condição em que os estudantes se situam em relação à construção das competências lingüísticas reunidas no foco leitura.

No que diz respeito ao conhecimento da variação lingüística, consideramos que a escola deve praticar uma pedagogia culturalmente sensível aos saberes dos alunos.

FONTE: BRASIL, 2006, p. 104.

O que seria essa "pedagogia culturalmente sensível”? Pelas análises feitas, não é possível afirmar categoricamente uma resposta.

TRECHO 15: heterogeneidade e inclusão, respeito, ensino crítico e variedades em pares dicotômicos.

É de se supor, então, que a habilidade de identificar as várias realizações da fala é fundamental para a inclusão dos alunos considerados lingüisticamente fora do processo ensino/aprendizagem. Importante, ainda, é que a escola pratique o respeito às características culturais e psicológicas dos alunos.

Bagno (2000) defende um ensino crítico da norma-padrão. Para ele, a escola deve dar espaço ao máximo possível de manifestações lingüísticas concretizadas no maior número possível de gêneros textuais e de variedades de línguas: rurais, urbanas, orais, escritas, formais, informais, cultas, não-cultas etc.

FONTE: BRASIL, 2006, p. 104.

Se o autor defendeu essa tipologia de ensino no ano 2000, também o fez em 2013. Para Bagno (2013, p. 67), "É preciso deixar claro, porém, que apesar de ser um produto cultural, [...] a norma padrão tem de ser incluída em qualquer estudo sobre as relações entre linguagem e sociedade. Só não pode ser, como tem sido, um lugar exclusivo e excludente".

A terminologia "norma-padrão" não é o mesmo que "norma culta" (BAGNO, 2013, p. 46). A "norma-padrão", inclusive, nem é uma "variedade" por não fazer parte do "espectro contínuo de variedades linguísticas reais, efetivamente faladas numa comunidade" (BAGNO, 2013, p. 61, grifos do autor). Já a "norma culta" é "o conjunto de variedades urbanas de prestígio realmente empregadas pelas camadas privilegiadas da população" (BAGNO, 2013, p. 63). Ademais, para "tratar do fenômeno da variação linguística de uma maneira razoavelmente satisfatória (e, mais ainda, para fazer uma transposição didática dele), é imprescindível o recurso aos instrumentos de análise oferecidos pela sociolinguística e pela sociologia da linguagem" (BAGNO, 2013, p. 47, grifos do autor).

Não sabemos se o autor realmente sustenta, conforme lhe é atribuída, a ideia de "manifestações linguísticas" dicotômicas como "variedades de línguas: rurais, urbanas, orais, escritas, formais, informais, cultas, não-cultas etc.". Primeiro, é de seu conhecimento, desde 1985, o trabalho de Bortoni-Ricardo e a proposição de variedades linguísticas dispostas num espectro contínuo e não mais extremizadas e desconectadas entre si (BAGNO, 2013, p. 61). Segundo, trata-se de "A língua de Eulália", obra na qual o autor apresenta uma crítica dessa visão dicotômica e propõe a noção de continuum dialetal (BAGNO, 2013, p. 78).

Finalizando essa seção, recorremos, mais uma vez, às palavras desse autor:

Traços de Linguagem, Cáceres, v. 4, n. 2, p. 102-116, 2020. 
"Temos então no Brasil uma situação, em certa medida, semelhante à das primeiras gramáticas produzidas no mundo de língua grega, no século III a. C.: desejosos de preservar a língua escrita da fase mais celebrada da literatura grega clássica (séculos VIII a V a. C.)" (BAGNO, 2013, p. 58).

\section{Considerações finais}

Recordando o objetivo de avaliar se e como o conteúdo do material da Prova Brasil, destinado aos professores de Língua Portuguesa, incorpora as contribuições da sociolinguística, concluímos ser elas aparentes, contudo, de forma limitada e portadoras de papel figurativo para a perpetuação do ensino de uma idealizada "língua-padrão", uma reprodução historicamente marcada desde Dionísio da Trácia, no séc. III a.C., com a elaboração da gramática da língua grega.

Os termos variação e mudança, embora estabeleçam relação, são empregados como equivalentes ou intercambiáveis, o que demonstra um equívoco dos elaboradores do material.

A variação linguística é vista como se existisse apenas na língua falada. É mensurada apenas em exemplares textuais escritos e considerados como reflexos dessa língua falada, porém inadequados ou inapropriados à escrita.

Quanto ao tema da "norma linguística", o manual adota o entendimento de que há uma só norma-padrão da língua, sendo as demais reprováveis.

Por fim, acerca da "pedagogia da variação linguística", o material reconhece a necessidade desse tipo de trabalho, mas, além de não caracterizá-lo, limita-se a sugerir uma lista de textos escritos(!) que seriam os mais apropriados para esse trabalho: as letras de música, tirinhas, revistas em quadrinho, trechos de diário e narrativas.

Em suma, ao divulgar essa compreensão dos aspectos da língua, os elaboradores do material demonstram manter um entendimento de língua com funcionamento homogêneo, uma visão já superada pelas contribuições sociolinguísticas. Ademais, se reproduzidos pelos professores em cada sala de aula, favoreceria a continuidade da geração e da circulação de mal-entendidos e preconceitos acerca da língua.

\section{REFERÊNCIAS}

BRASIL. Ministério da Educação. Prova Brasil: Apresentação. Disponível em: http://portal.mec.gov.br/prova-brasil. Acesso em: 19 jun. 2020.

. PDE: Plano de Desenvolvimento da Educação: Prova Brasil: ensino fundamental: matrizes de referência, tópicos e descritores. Brasília: MEC; SEB; INEP, 2011. 193 p. Disponível em: http://portal.mec.gov.br/prova-brasil/matrizes-da-provabrasil-e-do-saeb. Acesso em: 29 jun. 2020.

BELINE, Ronald. A variação linguística. In: FIORIN, José Luiz (org.). Introdução à linguística. São Paulo: CONTEXTO, 2002, p. 121-140.

BAGNO, Marcos. Sete erros aos quatro ventos: a variação linguística no ensino de português. São Paulo: PARÁBOLA, 2013.

BORTONI-RICARDO, Stella Maris. Educação em língua materna: a sociolinguística 
na sala de aula. São Paulo: Parábola, 2004.

CAMACHO, Roberto Gomes. Uma reflexão crítica sobre a teoria sociolinguística. D.E.L.T.A., São Paulo, v. 26, n. 1, p. 141-162, 2010. Disponível em: $<$ http://www.scielo.br/pdf/delta/v26n1/06.pdf $>$. Acesso em: 28 out 2016.

CHAGAS, Paulo. A mudança linguística. In: FIORIN, José Luiz (org.). Introdução à linguística. São Paulo: CONTEXTO, 2002, p. 141-163.

CEZARIO, Maria Maura; VOTRE, Sebastião. Sociolinguística. In: MARTELOTTA, Mário Eduardo (org.). Manual de Linguística. São Paulo: CONTEXTO, 2008. p. 14155.

GIL, Antônio Carlos. Como elaborar projeto de pesquisa. 4. Ed. São Paulo: ATLAS, 2008.

GÖRSKI, Edair Maria; VALLE, Carla Regina Martins. Variação discursiva: procedimentos metodológicos para delimitação do envelope de variação. In: FREITAG, Raquel Meister Ko; SEVERO, Cristiane Gorski; Sociolinguística e Política Linguística: Olhares Contemporâneos. São Paulo: BLUCHER, 2016, p. 79-99. Disponível em: <http://openaccess.blucher.com.br/article-list/sociolinguistica-epolitica-linguistica-302/list\#articles>. Acesso em: 28 out 2016.

GÜNTHER, Hartmut. Pesquisa qualitativa versus pesquisa quantitativa: esta é a questão? Psicologia: Teoria e Pesquisa, [s. 1.], v. 22, n. 2, pp. 201-210, Mai-Ago 2006. Disponível em: <http://www.scielo.br/pdf/ptp/v22n2/a10v22n2>. Acesso em: 30 out 2016.

LABOV, William. Padrões sociolinguísticos. Tradução Marcos Bagno, Maria Marta Pereira Scherre, Caroline Rodrigues Cardoso. São Paulo: Parábola Editorial, 2008. 392p. (Coleção Lingua[gem]; 26).

LEITE, Marli Quadros. A variação linguística. In: SILVA, Luiz Antônio da (org.). A língua que falamos: Português: história, variação e discurso. Rio de Janeiro: Globo, 2005, p. 183-205.

MODESTO, Artarxerxes Tiago Tácito. Formas de tratamento em São Vicente: julgamentos de valor. In: CARAMORI, Alessandra Paola (org.). Português ou Brasileiro: que língua é essa? São Paulo: ANNABLUME, 2004, p. 47-56. (Seleção de textos proferidos durante o VI Encontro dos Alunos de Pós-graduação em Linguística da Universidade de São Paulo - ENAPOL-, de 26 a 28 de novembro de 2003).

PRETTI, Dino. Sociolinguística: os níveis de fala: um estudo sociolinguístico do diálogo na literatura brasileira. 9. Ed. São Paulo: USP, 2003.

RODRIGUES, Aryon Dall'Igna. Problemas relativos à descrição do português contemporâneo como língua padrão no Brasil. In: BAGNO, Marcos (org.). Linguística da norma. 2. Ed. São Paulo: LOYOLA, 2006.

SILVA, Edila Vianna da. A pesquisa sociolinguística: a teoria da variação. Disponível 
em: <http://www.filologia.org.br/abf/rabf/9/049.pdf>. Acesso em: 27 out 2016 (pp. 49$57)$.

TARALLO, Fernando. A pesquisa sociolinguística. São Paulo, Ática, 1985.

Recebido em: julho de 2020. Aprovado em: setembro de 2020.

\section{Como citar este trabalho:}

BAUMGÄRTNER, C. T.; MENEGOLO, L. W. Variação linguística e Prova Brasil: quando o prescrito não dialoga com a reflexão teórica. Traços de Linguagem. v. 4, n. 2, p. 102-116, 2020. 